\title{
Identidade profissional na formação docente em contextos virtuais
}

\author{
Maria Fernanda González \\ Jorge Castro-Tejerina \\ Universidad Nacional de Educación a Distancia \\ Ana Paula Carlucci \\ Universidade de Brasília
}

\section{Resumo}

0 artigo analisa os significados mediadores da construção da identidade profissional docente em um fórum de discussão virtual. Partimos dos enfoques sociocultural e da teoria da atividade, realizamos um estudo empírico dos discursos produzidos por 32 estudantes e um tutor. Para tanto, realizamos três tipos de análises para estudar os conteúdos temáticos e as dinâmicas dos intercâmbios no fórum. Os resultados sugerem que os significados mediadores de ser professor se constituíram dialogicamente nas práticas de intercâmbios discursivas e se centraram no professor como agente e como mediador na transmissão do conhecimento e como bom e mau professor.

Palavras-chave: Identidade profissional. Formação docente. Contextos virtuais de aprendizagem. 


\section{Professional identity and teacher education in virtual contexts}

This article analyzes mediating meanings of the construction of teacher identity in a virtual discussion forum. We used the socio cultural and activity theory approaches. We conducted an empirical study of the discourses produced by 32 students and a tutor. For this, we performed three types of analyses to study subject area contents and the exchange dynamics in the forum. Results suggest that the mediating meanings around teacher identity are constructed dialogically through discursive practices and interchanges, and revolve around the teacher as the agent and mediator in the transmission of knowledge, and as a good and bad teacher.

Keywords: Professional Identity. Teacher Education. Virtual learning contexts.

\section{Identidad profesional en la formación docente en contextos virtuales}

El artículo analiza los significados que median la construcción de la identidad profesional docente en un foro virtual. Partiendo del enfoque sociocultural y la teoría de la acción, se realizó un estudio empírico de los discursos que produjeron treinta y dos estudiantes y un tutor. Realizamos tres tipos de análisis para estudiar los contenidos temáticos y las dinámicas de los intercambios en el foro. Los resultados sugieren que los significados sobre ser profesor se construyen dialógicamente en los intercambios discursivos y se centran en el profesor como agente y como mediador en la transmisión de conocimientos. También aparecen significados sobre ser buen o mal profesor.

Palabras-clave: Identidad Profesional. Formación Docente. Entornos Formativos Virtuales. 


\section{A identidade profissional do professor: reflexividade, compromisso e mediação}

No presente artigo, estudamos os significados mediadores de ser professor em contextos de formação profissional a distância. Nos últimos anos, enfatizase a formação dos docentes como profissionais reflexivos (Schön, 1992), isto é, capazes de analisar e de tomar decisões sobre sua prática profissional. Ao mesmo tempo, ressalta-se o valor da formação continuada do docente, relacionando-a a um certo modelo ideal do cidadão: aquele que busca melhorar suas habilidades e competências ao longo de sua vida.

No nosso trabalho, discutimos um aspecto pouco estudado no âmbito da formação docente universitária: a construção de significados de ser professor que acontece durante a formação nos ambientes virtuais. Os processos formativos, independentemente do nível educativo e dos conteúdos de que tratam, contribuem com dois processos inter-relacionados: por um lado, com a construção de significados sobre os conteúdos curriculares, ou aprendizagem e, por outro, com a configuração de novas identidades. (Wortham, 2004; 2010)

0 processo de apropriação de conhecimentos tem uma possível influência no modo em que cada pessoa percebe a si mesma (Wenger, 1998; 2010). Desde esse ponto de vista, o recurso à reflexividade se aplica não apenas ao fazer prático dos futuros professores, mas também a quem serão, isto é, ao próprio posicionamento subjetivo e identitário.

Os contextos educativos configuram-se como verdadeiras atividades socioculturais, isto é, como cenários fortemente sujeitos a regras, nos quais circulam ferramentas culturais, tais como os significados vinculados ao ser professor - inseridos, por sua vez, em um contexto e uma história específicos -, e nos quais se desenvolvem práticas concretas que favoreçam formas particulares de relação e de construção da comunidade (de la Mata; Santamaría, 2010). A identidade do futuro professor e do aprendiz encontra sua origem nas experiências de participação em atividades de aprendizagem. (Coll; Falsafi, 2010)

Alguns autores inclusive propõem que estes cenários educativos são verdadeiras “zonas de desenvolvimento proximal da identidade" (ZDPI) (Polman, 2010), já que os estudantes participam de atividades que são centrais aos processos de negociação identitários. Deste modo, o processo formativo é parte das trajetórias de identificação (Polman, 2010) por meio da participação em diferentes comunidades de práticas (Wenger, 1998), nas quais se estabelecem conexões entre modelos identitários presentes e passados.

Assim, ao longo da participação nos processos formativos constrói-se uma 
identidade de aprendiz (LI: Learning Identity) que é, ao mesmo tempo, estável e mutável. A estabilidade é atingida a longo prazo, enquanto, ao enforcarmos cenários educativos concretos, poderemos perceber as mudanças e transformações próprias de atuações identitárias e de atos de identificação mútuo entre os aprendizes. (Coll; Falsafi, 2010)

Coll e Falsafi afirmam que, nos ambientes virtuais, estes atos de identificação fazem, por exemplo, referência explícita à opinião de um companheiro, a respostas a uma intervenção anterior, à obtenção de opinião e acordos entre os companheiros, etc.

No nosso caso, ademais, entendemos que a identidade do aprendiz articula-se ao redor de dois momentos temporais, considerando-se que os participantes na formação são aprendizes em contextos formativos concretos que, por sua vez, se constroem como futuros professores, por meio da negociação de modelos identitários.

Trabalhos (Wortham, 2006; de la Mata; Santamaría, 2010; Wenger, 1998) afirmam que a configuração identitária do aprendiz é favorecida pela participação conjunta em atividades de aprendizagem. Em grande medida, esta participação toma a forma de trocas discursivas e comunicativas, sobretudo, quando ocorridos em ambientes virtuais.

A partir de indagações sobre as particularidades que introduzem a mediação das chamadas novas tecnologias nos processos formativos e, em especial, na configuração das identidades dos futuros professores, buscamos, neste trabalho, oferecer alguns elementos de análises teóricos e empíricos sobre essas relações.

Partimos do pressuposto de que as tecnologias de informação e comunicação (TICs) introduzem novas formas de mediação da atividade humana, que afetam não apenas a organização material da atividade, mas também a organização simbólica e, com certeza, os sujeitos que dela participam.

No curso da experiência e da ação humana, a introdução das TICs supõe uma modificação qualitativa (Wertsch, 2002) na atividade humana. Algumas dessas mudanças podem ser imprevisíveis e serão vistas à medida que as tecnologias forem inseridas nos diferentes ambientes sociais, como o educativo. Entretanto, algumas mudanças já são evidentes. Por exemplo, com a prevalência da comunicação escrita nos ambientes virtuais, como os fóruns, está sendo promovido o surgimento de metacomentários de um modo diferente da comunicação oral e, com isso, a reflexão metacognitiva.

O caráter assincrônico da comunicação nos fóruns virtuais permite que os participantes possam demorar ou suspender temporalmente a comunicação e, desta forma, ter o tempo de que necessitam para responder a uma intervenção, fazer uma pergunta, um comentário ou introduzir um tema de debate. Estas 
propriedades, cruciais em toda a comunicação social, surgem com o uso destas novas formas de mediação.

A atividade se transforma pela mediação das TICs, enquanto artefatos que levam consigo sua própria história e que criam novas formas culturais, visto que os artefatos também introduzem novas formas de controle e organização da atividade e da própria consciência da atividade. (Nardi, 1996; Nardi; O'Day, 1999; Kaptelinin; Nardi, 2006)

Todos esses processos podem ser representados, em suma, por meio do triângulo mediacional básico proposto por Engeström (1987) como aplicação das teorias vigostkianas (Cole, 1999) e adaptados, no nosso caso, à construção virtual de identidades por meio das TICs.

Figura 1: Processo de configuração identitária em um espaço virtual segundo a teoria da atividade

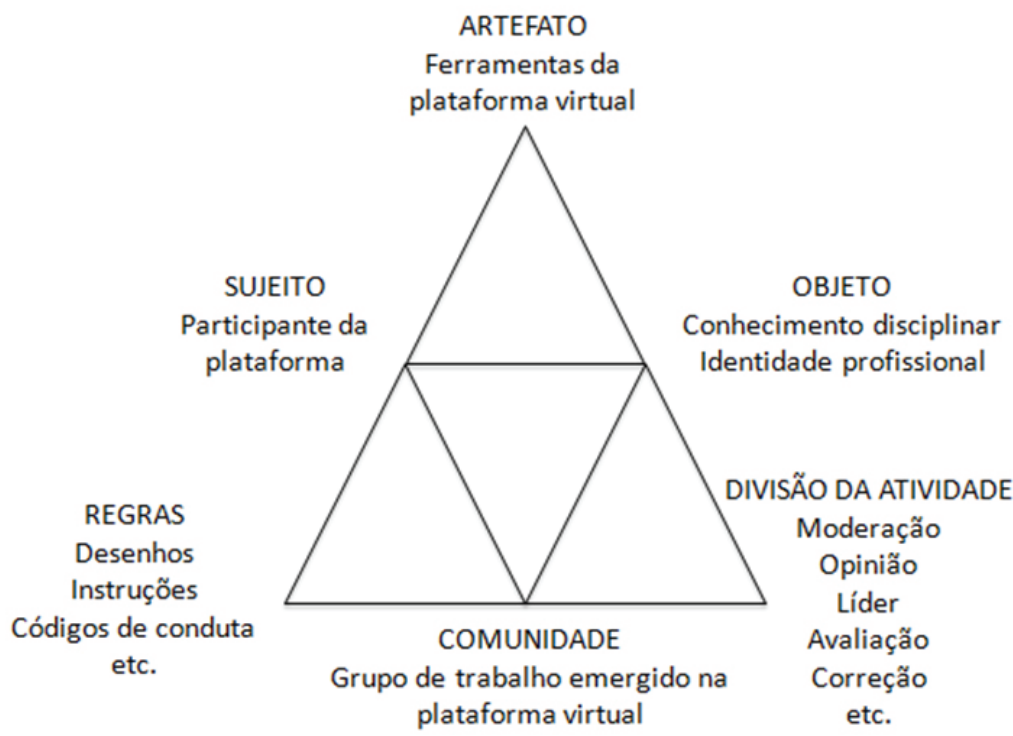

Fonte: Engeström. (1987, p. 166)

\section{Condições para a construção de identidades nos entornos virtuais}

Ao enfocarmos a análise das dinâmicas de inter-relação identitárias derivadas do modelo proposto, partimos de três elementos apontados: sujeito, artefato e objeto. 0 primeiro elemento do triângulo mediacional que analisaremos é o 
sujeito. No mundo virtual, pode se entender o sujeito como a entidade que negocia recursos da rede e possibilidades identitárias, com consciência mais ou menos estratégica ou distante em relação a si-mesmo.

Nos fóruns, o sujeito revela os dados mais íntimos de sua vida real, até jogos, nos quais pode assumir os atributos de um cavaleiro medieval, alienígena, espião, etc, passando por fóruns, nos quais simula ser outra pessoa. Em todos esses casos, a identidade apresentada concretiza o que o sujeito ou o Eu é em um contexto, uma situação ou, inclusive, em uma interação concreta e na ausência, neste caso, do corpo real. (Turkle, 1997)

Como temos visto, a comunicação virtual, e, dentro dela, a educativa, também gera um contexto sociocultural delimitado por regras, normas e condições de possibilidades. Dentre elas, podemos destacar que estão, implícita ou explicitamente, inscritas no desenho material dos dispositivos o espaço material e virtual da interação, a condição sequencial ou demorada do uso das aplicações, os códigos explícitos de manejo ou comportamento, as normas surgidas e estabelecidas por meio da interação. (Aycock, 1995; Riva; Galimberti, 2001)

Como em qualquer ecologia humana (Nardi; O'Day, 1999), estas condições e regras permitem multiplicidade de recursos para decidir, criar, imaginar ou construir atos de identificação (Rosa; Blanco, 2007) no espaço virtual, mas também restringem as possibilidades. Neste sentido, aparecem as limitações nos intercâmbios metacomunicativos e pragmáticos próprios do encontro presencial (gestos, entonações, etc.), ao mesmo tempo em que supõem uma mudança radical ou, inclusive, revolucionária, no que se refere aos tempos (mais acelerados) e alternativas (múltiplas) da circulação da informação e das experiências identitárias.

Todos esses processos são radicalmente inovadores e se relacionam com o encontro do sujeito com o "si-mesmo" - autotechnopoiesis - (Capurro, 1996; Valentine, 2000; Dervin; Abbas, 2009). Em suma, esses processos são práticas até o momento inéditas na história da humanidade, mesmo quando, como veremos, conectam funcional e genealogicamente com atividades identitárias e tecnológicas comunicativas mais antigas.

0 segundo elemento que analisaremos dentro do sistema de atividades são os artefatos. Neste sentido, os fenômenos identitários de adscrição do sujeito a um determinado sistema de valores ou pautas de atividades dependem inextricavelmente de recursos e artefatos culturais que os veiculem.

Estudos (Nardi, 1996; Turkle, 2004) distinguem os artefatos implicados na constituição de comunidades e identidades virtuais entre os artefatos materiais como o monitor e o teclado do computador, o grafismo da escrita e a imagem na tela ou o som de uma canção em MP3 - e os simbólicos - como o significado e o sentido do lido, escrito ou ouvido diante do computador, os próprios usos e funções 
das ferramentas materiais e os procedimentos, já que o como usar e o para quê e por que são práticas culturais de uso de artefatos. Como meios materiais e simbólicos da interação, colaboram na abertura e estabilização das experiências do si-virtual.

Desde a nossa perspectiva, as formas tradicionais da oralidade e da escrita encontram sua continuidade nos modos híbridos de comunicação nos ambientes virtuais (Langham, 1994; Capurro, 1996; Karge, 1999). Atentando à coconstrução de identidades e comunidades virtuais, neste artigo nos interessa enfocar especialmente a condição multimodal da interação virtual (escrita, vídeo, música, emoticons, realidade virtual, simulação, avatares etc.) e o tipo de operações permitidas ao sujeito.

Outros estudos (Karge, 1999; Riva; Galimberti, 2001) apontam que a interação e a comunicação mediada pelas tecnologias de informação e comunicação transformam a escrita isolada em uma rede virtual de hipertextos de leitores e escritores, pois conecta e aproxima as pessoas separadas geograficamente na internet.

Nesse novo cenário, o contexto e as dinâmicas identitárias oportunizadas pela internet devem ser observados em continuidade genealógica com formas de gestão e configuração identitárias prévias - mnemônicas, diários, livros de horas, manuais, etc. Ademais, a interação estabiliza uma estrutura de relação e uma história comum que, também na microcultura, pode ser analisada a partir das conexões, tessituras e textos de mensagens presentes no fórum. (Cutler, 1996)

Ao longo do tempo de vida do fórum, os sujeitos utilizam conhecimentos derivados de suas experiências no espaço virtual - e fundamentam neles seus atos de identificação, até quando se dedicam a escrever seus próprios textos ou intervir nos textos dos outros participantes do fórum.

No mundo virtual há, em definitivo, histórias e complexos identitários que são continuamente construídos e compartilhados por comunidades e que oferecem suporte em um artefato a meio caminho entre as formas e potencialidades da oralidade e as da leitura-escrita.

As interações mediadas pela comunicação virtual fomentam necessariamente a democratização e, como debatido ferozmente por muitos autores, o fundamentalismo, o individualismo, o gregarismo, ou qualquer outro tipo de dimensão ético-política que tanto nos alertam em tempos de pós-modernismo e globalização. (Capurro, 1996)

As dinâmicas, objetivos e consequências identitárias de uma comunidade virtual podem ser muito diversas, dependendo tanto do conteúdo como das formas; como também do que ocorreu no passado nos contextos de socialização orais e escritos.

Por último, analisaremos o terceiro elemento do triângulo mediacional, 
representado pelo objeto entendido por nós como a própria identidade ou identidades virtuais geradas no processo interativo. Como mencionado anteriormente, os estudos sobre identidade são marcados pela perspectiva hermenêutica e discursivista, que vinculam a identidade a aspectos, sobretudo, linguísticos. (Rosa; Blanco, 2007; Bruner, 1998; Wertsch, 1993; Harré, 1998)

As opiniões têm sido múltiplas, embora normalmente todas utilizem a linha bahkiniana e assumam que a identidade se constrói além do sujeito individual, por meio do diálogo ou do encontro discursivo e de vozes disponíveis na cultura, de forma mais ou menos concreta, pelos outros. A linguística transporta, assim, as dimensões contextuais, culturais, coletivas e semióticas, situando-se na origem dos significados culturais compartilhados pela comunidade; os mesmos que, em última instância, constituem a base da construção identitária.

Nesta mesma linha linguística e semiótica, considera-se que as estruturas biográfico-narrativas são as que melhor caracterizam esse processo de construção identitária. Revelam seu caráter temporal e, até certo ponto, dramatúrgico, imaginativo ou fictício, que adquire sentido em contextos de práticas concretas tais como acontecem, no nosso caso, nos ambientes virtuais de aprendizagem.

Os estudos da identidade virtual partem, em sua maioria, dos pressupostos discursivistas. Nisto, revela-se o papel crucial que cumpre, precisamente, a escritura no contexto virtual. Entretanto, é necessário destacar dois aspectos do caráter linguístico da construção de identidades virtuais, um relacionado à narratividade e outro à multivocalidade.

1) Narratividade: o discurso possui uma importância chave no intercâmbio dos sentidos e da construção semiótica da identidade no espaço virtual, porém, cabe mencionar que a identidade virtual se produz para além de uma via exclusivamente narrativa ou discursiva. É evidente que se podem utilizar formas argumentativas que não obedecem à organização cronológica e narrativa da atividade. Existem formas poético-metafóricas ou de grande abstração conceitual que também podem transportar atos de identificação e gerar processos de coconstrução identitária.

Além disso, há formas de navegação no espaço virtual que respondem prioritariamente a uma lógica espaço-simultânea mais que sequencialnarrativa. 0 sujeito vai desenvolvendo sua atividade e identidade, manejando e categorizando bases de dados e objetos semióticos organizados topologicamente. Este processo promove interações e atuações identitárias que se parecem mais a uma trajetória na qual se combinam objetos (usados) do que a uma sucessão narrativo-temporal de acontecimentos (dá sentido). (Ver Kress, 2003)

2) Multivozes: a construção dialógica da identidade não se produz apenas no 
contexto virtual, já que este se insere e se mistura com as dinâmicas mais gerais do mundo real, dos espaços socioculturais mais amplos dos quais participa - e pode participar - o sujeito. De fato, a controvérsia que, desde o ponto identitário, provoca a internet tem a ver com a abertura e contato genuíno com/entre as multivozes do contexto global. Nele se permite a possibilidade de manejar múltiplas identidades e decidir o grau de responsabilidade sustentado com elas.

Em certo sentido, a internet oferece cosmovisões alternativas que garantem a estabilidade da comunidade real (Dervin; Abbas, 2009; Haste, 2009). Num certo sentido, a internet oferece cosmovisões alternativas àquelas que garantem estabilidade da comunidade real (Dervin; Abbas, 2009; Haste, 2009), aproximando qualquer pessoa capaz de manejar as TICs a uma tomada de consciência desta multivocalidade e à possibilidade de gerenciá-la.

Oferece também a possibilidade de empoderamento, de escolha dos modos de relação entre a sua comunidade e aquela imaginada da realidade geopolítica - seu país, sua etnia, seu estado, nação, sua família - e as comunidades emergentes no mundo virtual desterritorializado (Valentine, 2000; Haste, 2009). Sendo assim, acreditamos que das multivozes do espaço virtual se desprendem duas consequências básicas para a construção de qualquer identidade virtual.

Em primeiro lugar, a comunidade virtual não é universal nem inerentemente isolada ou socializadora, individualista ou comunitária, hierárquica ou igualitária, reacionária ou liberal, democrática ou fundamentalista, alienante ou liberadora, intimista ou exibicionista, cosmopolita ou localista, etc. como discutem e tratam de resolver muitos autores (Vattino, Habermas, Lyotard, etc.). 0 que é evidente é que nela podem ser veiculadas todas essas alternativas como o fizeram, ao longo da história, outras tecnologias do Eu individual e coletivo.

Em segundo lugar, as múltiplas possibilidades identitárias - e, como as, ético-políticas - à disposição do sujeito não implicam a existência de espaços identitários imutáveis e impermeáveis.

Os estudos sobre identidade profissional mostram que há uma contínua interpenetração e movimento - em diferentes graus e modos - entre as formas identitárias relacionadas ao público (trabalho, escola, etc.) e as conectadas com o privado (família, filiação política ou religiosa, etc.). No marco da interação da comunicação virtual, a mistura, de fato, alcança possivelmente a sua máxima expressão. A informalidade, aceleração, imediatez e condição efêmera das enunciações fomentam interpenetração de espaços identitários aparentemente fragmentários. 


\section{Um estudo exploratório da construção identitária virtual do docente em um contexto virtual}

No estudo empírico, apresentamos a análise dos significados mediadores em relação à futura identidade profissional docente e às dinâmicas de intercâmbio e comunicação estabelecidas para a criação de comunidade, em um fórum da disciplina da formação docente universitária!.

Neste artigo, objetivamos analisar os significados das múltiplas opções identitárias que os aprendizes constroem nos ambientes on-line em relação às formas de modelos de professor sustentadas pelas múltiplas vozes e tradições; e, por outro lado, caracterizar os intercâmbios discursivos estabelecidos nesses ambientes analisando, com atenção, o surgimento de indicadores de reflexividade e do reconhecimento mútuo entre os aprendizes.

Para isso, trabalhamos com a disciplina Psicologia e Escola ofertada para estudantes do segundo bimestre do primeiro ano do curso de Licenciatura em Letras-Português da Universidade Aberta do Brasil na Universidade de Brasília (UAB/UnB), Brasil. Ressaltamos que a UAB é um sistema implementado nas instituições de ensino superiores (IES) públicas, por meio de programa de graduação, extensão e pós-graduação, criada em 2005, pelo governo brasileiro para atuação na formação inicial e continuada de professores da educação básica. Sua criação pauta-se no compromisso de expandir a oferta, interiorizar e democratizar o acesso à educação pública de qualidade, além de permitir o acesso a uma formação inicial e a uma formação continuada de qualidade aos futuros profissionais e professores.

A UAB/UnB foi implementada em 2005 e utiliza-se de modelos pedagógicos baseados na tecnologia de multimídia e interatividade, por meio da plataforma Moodle, um software livre, para gestão das aprendizagens e de trabalho colaborativo, que permite a criação de cursos on-line, páginas de disciplinas, grupos de trabalho e comunidades de aprendizagem - uma ferramenta simples, fácil de usar e de modificar, que uniformiza a inserção dos conteúdos na web. (Flores; Flores, s/a)

0 planejamento da disciplina seguiu as atividades planejadas nas versões anteriores: dois fóruns de discussão e duas atividades avaliativas. No entanto, na pesquisa, há duas diferenças em relação às versões anteriores: cada fórum ficou aberto por três semanas e, nas atividades avaliativas, incluímos uma terceira opcional: a criação do blog sobre identidade docente.

A disciplina teve a duração de oito semanas, com 60 horas de carga horária, com

1. Para a elaboração de este artigo, partimos dos resultados apresentados no II Congresso em Educação e TIC em Lisboa/Portugal, ano 2012, e aprofundamos as análises e a discussão para fins de publicação na revista Linhas Críticas. 
a participação de 100 estudantes, divididos entre quatro turmas. Para o presente artigo, analisamos o primeiro fórum de discussão, da Turma A da disciplina, com 32 estudantes e com 44 postagens. Nele procuramos relacionar o conteúdo que estava sendo estudando na disciplina, referente às teorias do desenvolvimento humano e da aprendizagem, com o nosso interesse no estudo: construção da identidade docente na educação a distância.

A escolha do primeiro ano de curso deu-se por dois motivos: o primeiro, para verificarmos o impacto da educação a distancia, ou seja, do uso de novas tecnologias na construção da identidade docente, visto que a maioria dos estudantes não tinha experiência anterior com o uso de computador ou desconhecia plataformas de aprendizagem; e o segundo, por estarem cursando a segunda disciplina da Psicologia, ou seja, com, ao menos, 08 semanas iniciais de experiência de estudo na área de conhecimento com as TICs.

0 comando do fórum foi feito da seguinte maneira: na primeira semana, os estudantes debateram e aprofundaram conceitos trabalhados na disciplina; na segunda, os tutores abriram um novo tópico no fórum de discussão e inseriram uma reportagem de impacto relacionada com aspectos controvertidos da prática profissional docente. Neste momento, queríamos gerar a participação ativa dos estudantes, enfocando questões identitárias e morais, a fim de percebemos como eles se posicionam e eram posicionados nas narrativas. Na última semana, os tutores encerraram as discussões resumindo as principais contribuições da turma.

Para analisar as interações no fórum, realizamos três tipos de análises, que buscam estudar tanto os conteúdos temáticos ou significados identitários quanto as dinâmicas que se produzem durante os intercâmbios no fórum. Na primeira análise, a sincrônica, realizamos a caracterização temática dos significados ou conteúdos construídos e compartilhados pelos participantes em suas entradas no primeiro fórum de discussão. Desta análise, criamos cinco categorias distintas para os temas postados por cada um dos interlocutores no fórum: identidade, motivação, contexto, finalidade e outro-estudante.

Os significados dentro da categoria identidade fazem referência a quem é o professor e o que é necessário para ser professor. Em relação à motivação, os significados referem-se ao motivo pelo qual a pessoa escolheu a profissão docente. No que tange à categoria contexto, os significados referem-se a onde e quando o trabalho docente é realizado. Na categoria finalidade, os significados referem-se às ações que o professor precisa fazer para realizar seu trabalho. Por último, a categoria outro-estudante traz os sentidos construídos pelos futuros estudantes sobre o ser estudante.

Ainda para esse momento da análise sincrônica, consideramos o conjunto 
de mensagens de cada participante como um texto único, em que as passagens inteiras ou parágrafos estão sendo transformados em categorias sintéticas. Estas enunciações são, em seguida, categorizadas em palavras-chave ou categoriaschave.

Na segunda análise, a diacrônica, analisamos as entradas, de forma cronológica, de cada um dos participantes e fizemos um mapa temporal com os números das intervenções e das dinâmicas estabelecidas entre elas, tanto em relação aos estudantes que interagiram entre eles quanto aos que não interagiram e somente postaram uma mensagem.

Para a análise diacrônica, adaptamos a análise da conversão aplicada à psicologia (Pontecorvo, 2005), com as três seguintes categorias: 1) réplica simples, na qual o estudante menciona o colega, concorda com ele, mas não especifica com o que está concordando; 2) réplica elaborada, em que o estudante menciona o colega, concorda com ele e elabora sobre o que está concordando, acrescentando outras informações; e 3) réplica com contra-argumentação e justificação, na qual o estudante menciona o colega, contra-argumenta e justifica o novo argumento. Na terceira análise, o turno enunciativo, consideramos a ordem das intervenções: os dias e a hora, se era a primeira vez ou as seguintes intervenções de entrada no fórum, e finalmente se nessas intervenções os estudantes aludem ou não às intervenções dos companheiros.

A partir dessas categorias, procuramos identificar quais significados estavam formando cada categoria; por exemplo, das enunciações de cada participante, quais significados estavam gerando o sentido de ser professor, e assim por diante.

Por último, e para estudar o funcionamento do fórum, estabelecemos uma relação entre as três análises: a do turno enunciativo, a diacrônica e a sincrônica. Analisamos se os estudantes interagiram ou não entre eles de forma cronológica e se, nessas interações, eles fizeram réplicas simples e/ou réplicas elaboradas ou com contra-argumentação e justificação aos colegas e se utilizavam das categorias temáticas geradas no próprio discurso do fórum para mediar e gerar a construção da identidade docente.

Os resultados apresentados referem-se aos três primeiros níveis de cada uma das três análises. Na primeira, de turno enunciativo, notamos que, apesar de 0 número total de estudantes na turma analisada ter sido 32, somente 22 estudantes participaram no fórum, pelo menos uma vez. Destes 22, 13 interagiram entre eles e no total houve 44 entradas no fórum, contando com a entrada da tutora. Nas análises sincrônicas e diacrônicas, incluímos apenas aquelas entradas que faziam menção a opiniões ou intervenções de outros estudantes ou da tutora. Na tabela 1, apresentam-se os resultados das análises diacrônicas e sincrônicas. 
Tabela 1: Frequências de dinâmicas e conteúdos das intervenções no fórum

\begin{tabular}{c|l}
\hline $\begin{array}{c}\text { Categorias análises diacrônicas: } \\
\text { dinâmicas }\end{array}$ & $\begin{array}{c}\text { Categorias análises sincrônicas: } \\
\text { conteúdo }\end{array}$ \\
\hline $\begin{array}{c}\text { a) réplicas simples: } \\
06 \text { intervenções }\end{array}$ & $\begin{array}{l}\text { - contexto: } 05 \text { menções } \\
\text { - identidade: } 03 \text { menções } \\
\text { - outro: } 01 \text { menção } \\
\text { - motivação: } 01 \text { menção }\end{array}$ \\
\hline b) réplica elaborada: & $\begin{array}{l}\text { - contexto: } 03 \text { menções } \\
\text { - motivação: } 02 \text { menções } \\
\text { - identidade: } 01 \text { menção } \\
\text { - fintervençõdade: } 01 \text { menção } \\
\text { - outro: } 1 \text { menção }\end{array}$ \\
\hline c) réplica com contra-argumenta- & - motivação: 02 menções \\
ção e justificação: 02 intervenções & identidade: 01 menção \\
\hline
\end{tabular}

Fonte: Carlucci; González; Castro-Tejerina (2012, p. 2228-2239).

Um primeiro resultado a ser destacado é que são poucas as intervenções (13 sobre um total de 44) nas quais há um reconhecimento mútuo de opiniões de outros estudantes e da tutora. Isto indica que os estudantes tendem a realizar intervenções únicas nas quais manifestam suas opiniões ou contribuições sem dialogar nem estabelecer comunicações com outros participantes.

$\mathrm{Na}$ análise diacrônica, em relação às três categorias - réplica simples, réplica elaborada e réplica com contra-argumentação e justificação - observamos que a primeira categoria - réplica simples - foi a mais realizada pelos estudantes, com seis intervenções, no total. Dentre esta categoria, as temáticas mais mencionadas foram, nesta ordem: contexto, identidade, outro e motivação.

Em seguida, a réplica elaborada, com cinco entradas, no total, em que os estudantes mencionaram o contexto, a motivação, e a identidade, finalidade e outro. Por último, a réplica com contra-argumentação e justificação; apesar de só terem ocorrido duas intervenções, as temáticas mais mencionadas foram: motivação e identidade. Os temas anunciados correspondem às categorias das 
análises sincrônicas, como assinalado na tabela 01.

Outro resultado significativo indicou que as trocas no fórum foram predominantemente de concordâncias, com apenas duas trocas de discordância. Muitas dessas concordâncias se deram em relação à identidade docente, ao contexto prático de sua profissão e às motivações.

Como exemplos dessas concordâncias, vamos comentar duas réplicas elaboradas e uma contra-argumentação e justificação para demonstrar como os estudantes construíram os significados sobre o ser professor no fórum virtual. Informamos que em todos os exemplos foram mantidas a digitalização produzida pelos estudantes.

Exemplo 1: Réplica elaborada

\begin{tabular}{|c|c|l|l|}
\hline 06 junho & Erenice & $\begin{array}{l}\text { Primeira } \\
\text { postagem. } \\
\text { Mensagem 30. } \\
\text { Menciona a } \\
\text { Helena. }\end{array}$ & $\begin{array}{l}\text { Boa noite! Concordo com a Helena, } \\
\text { o professor e raiz desde o inicio de } \\
\text { sua formação educacional, cabe } \\
\text { também o aluno exerce sua pratica } \\
\text { de aprendizado em seu cotidiano. }\end{array}$ \\
\hline
\end{tabular}

Fonte: Carlucci; González; Castro-Tejerina (2012, p. 2228-2239).

Neste exemplo, nota-se que Erenice menciona Helena ltodos os nomes são fictícios), concorda com ela sobre quem é, a função e a finalidade do professor, mas não retoma exatamente a enunciação de Helena e acrescenta o aluno (sua função e relação na aprendizagem). Neste exemplo, verificamos a categoria identidade como regulada e mediada pela tensão na identidade docente tradicional, ou seja, "professor como principal agente da localização", "instrução" e "transmissão do conhecimento".

Outros significados identificados nesses intercâmbios em relação à identidade docente são: "peça-chave da aprendizagem"; "agente transmissor do conhecimento"; " portador do saber", “guia máximo da aprendizagem” e o "principal pilar da educação"; "raiz da formação educacional do aluno"; "transmissor do conhecimento"; "foco da atenção"; "leva a reconstruir as estruturas" e a "construir outras novas"; "leva o aluno a ser pesquisador"; "arte de repassar seus conhecimentos para outras pessoas"; "transmite e falicita o conhecimento"; e a visão construtivista, principalmente em relação ao significado do ser estudante, como "participante ativo da aprendizagem", em que ele "constrói o conhecimento constantemente, conforme sua utilização, suas experiências, seu percurso formativo e profissional". 
Outro exemplo que merece a nossa atenção refere-se à segunda categoria, sobre a réplica elaborada.

Exemplo 2: Réplica elaborada

\begin{tabular}{|c|c|l|l|}
\hline 03 junho & \multirow{2}{*}{$\begin{array}{l}\text { Susana dia, concordo com você Carla, } \\
\text { Primeira }\end{array}$} & $\begin{array}{l}\text { Bom } \\
\text { cabe ao professor várias funções, } \\
\text { postagem. } \\
\text { Mensagem 11. } \\
\text { Menciona a Carla }\end{array}$ & $\begin{array}{l}\text { inúmeras respondabilidades e se } \\
\text { preparam cada vez mais para novas } \\
\text { funções. Abraços. }\end{array}$ \\
\hline
\end{tabular}

Fonte: Carlucci; González; Castro-Tejerina (2012, p. 2228-2239)

Neste exemplo, observa-se como Susana concorda com Carla retomando a questão das várias funções que são demandadas do professor e acrescenta que, nelas, o professor "tenta se equilibrar nas inúmeras responsabilidades" e "se preparar cada vez mais para as novas funções". Em postagens como esta, identificamos a categoria identidade regulando e mediando a construção da identidade docente, em que eles compartilharam e negociaram a concepção do docente como "polivalente" e "multifacetado", em "constante formação e reflexão profissional" para "dar conta das novas exigências e funções demandas pelo contexto sociocultural".

Outro exemplo de troca que merece destaque, diz respeito à terceira categoria, sobre discordância entre os estudantes:

Exemplo 3: Réplica com contra-argumentação e justificação

\begin{tabular}{|c|c|c|c|}
\hline $\begin{array}{l}12 \text { junho } \\
23 \text { h05 }\end{array}$ & Maria & $\begin{array}{l}\text { Terceira postagem } \\
\text { Mensagem } 40 . \\
\text { Menciona Erika e } \\
\text { André }\end{array}$ & $\begin{array}{l}\text { Certamente Erika e André o professor } \\
\text { tem que ter carinho pela sua profissão, } \\
\text { mas muito simplesmente estão nessa } \\
\text { area por falta de opção ou mesmo por } \\
\text { que seus pais queserão que fosem } \\
\text { ou seguise a tradição da familia onde } \\
\text { todos se formaram professores. Uma } \\
\text { falha muito grande, pois a maioria não } \\
\text { estão realizados profissionalmente } \\
\text { tornandos pessoas amarguradas que } \\
\text { não conseguem repasar corretamente } \\
\text { o que aprenderam a seus alunos. }\end{array}$ \\
\hline
\end{tabular}

Fonte: Carlucci; González; Castro-Tejerina (2012, p. 2228-2239) 
Neste exemplo, nota-se que Maria menciona Erika e André, concorda com eles em relação aos sentimentos pela profissão, mas se opõe a eles e oferece outro argumento sobre o ser professor e sua realidade concreta, menciona os professores que estão na profissão por "falta de opção" ou por "tradição familiar". São "professores amargurados" que "não conseguem repassar corretamente o conhecimento". Nesse exemplo, verificamos a categoria motivação regulando e mediando a construção da identidade docente, em que eles compartilham e negociam duas concepções distintas de ser professor. De um lado, a concepção de que, para ser docente, é preciso que o professor tenha sentimentos positivos pela profissão, ou seja, "tenha carinho". Por outro lado, a ideia de que muitos professores escolhem a profissão ou por falta de opção ou por tradição familiar, ou seja, que a escolha pela profissão não se faz apenas por sentimentos "nobres", mas também por "questões sociais, familiares, econômicas, dentre outras", que neste caso se referem a aspectos sociais (falta de opção) e familiares (tradição familiar).

Como podemos observar, no nosso estudo, notamos alguns temas ou conteúdo elaborados no próprio fórum virtual, e as dinâmicas foram sendo estabelecidas quando os estudantes - futuros professores - trocavam suas opiniões sobre a atuação e a identidade docente.

Em relação aos conteúdos, eles foram centrados em três categorias: contexto de atuação, motivação e identidade docente. Os conteúdos foram elaborados de acordo com os diferentes modelos de professor presentes nas diferentes tradições de formação prática docente no Brasil, que, no nosso caso, estão explícitos nas negociações estabelecidas entre os estudantes, tutor e conteúdo.

Nessa interação, notamos que, à medida que os estudantes se posicionavam e posicionavam os demais ao longo das sequências de mensagens no fórum virtual, eles foram se tornando socialmente identificados em função de diferentes modelos identitários. Por um lado, foram se constituindo como multifacetados e polivalentes e em constante formação e reflexão profissional, como podemos verificar anteriormente nos resultados. Por outro lado, como professores tradicionais, constituíram-se como transmissores do conhecimento, guia máximo, principal pilar.

0 mesmo movimento está acontecendo em relação à visão do estudante no processo de aprendizagem: ora passivo, ora ativo. Mas, mesmo enunciando ter uma visão ativa de estudante, enunciam também que o professor precisa, num primeiro momento, desenvolver a postura ativa do aluno; aí, sim, ele irá aprender a ser ativo e se tornará um estudante participativo. Mesmo neste momento a figura do professor é importante, é o centro da ação.

Por último, em relação às dinâmicas de comunicação e participação analisadas 
diacronicamente, podemos destacar os seguintes resultados: por um lado, ao menos em nosso fórum virtual, os intercâmbios comunicativos genuínos lentre dois ou mais companheiros e a tutoral foram escassos, embora a maioria dos estudantes participasse no fórum. Isto pode ser interpretado de várias maneiras.

Em primeiro lugar, os estudantes têm ainda pouca experiência na formação virtual universitária e, por isso, podem estar pouco familiarizados com as ferramentas virtuais (neste caso, o fórum) e com os formatos de comunicação que ali se utilizam. Em segundo lugar, o tipo de participação pode ter sido impactado pelas regras anunciadas pelos formadores (tutora e as professoras responsáveis da disciplinal em relação à avaliação: os estudantes deveriam participar, ao menos, duas vezes durante a duração do fórum, mas não se pedia explicitamente que retomassem ou comentassem as opiniões dos demais.

Ainda, os resultados obtidos sugerem que a construção de significados sobre o ser professor no fórum virtual deu-se, principalmente, por meio da concordância entre os participantes. Nos únicos dois exemplos de discordância, as categoriaschave que mediaram e geraram a construção do sentido de ser professor no fórum dizem respeito à motivação, como podemos verificar nos resultados, em que parece que a escolha da profissão impacta os sentimentos positivos e/ou negativos em relação à profissão. Neste sentido, a pouca atenção aos argumentos dos outros participantes e o escasso debate que se estabeleceu ao longo do fórum fizeram com que aparecessem poucas intervenções reflexivas e metarreflexivas sobre a condição de professor ou da própria atividade desenvolvida no fórum.

\section{Conclusões}

Neste artigo, apresentamos uma série de elementos teóricos e empíricos que podem ajudar a caracterizar a construção da identidade docente nos contextos formativos virtuais.

Segundo o modelo proposto, a construção da identidade docente se constitui em diferentes trajetórias que transitam em tipos de práticas e discursos, entre elas, as formativas. Como em toda atividade sociocultural, os contextos formativos configuram-se e relacionam-se com diferentes elementos entre os quais destacamos o sujeito-aprendiz, os artefatos materiais e simbólicos e a própria identidade como objeto que se constrói conjuntamente na relação.

Nos contextos formativos - no nosso caso, o virtual - se constroem conhecimentos ao mesmo tempo em que se articulam diferentes trajetórias identitárias (Coll; Falsafi, 2010). Como afirmamos anteriormente, a identidade do aprendiz constrói-se dialogicamente por meio da participação nas práticas de 
intercâmbios discursivas, como as que são produzidas no fórum estudado.

Nele se fazem presentes diferentes significados sobre a identidade e a prática docente, provenientes dos processos de troca entre o mundo real (por exemplo, as diferentes imagens sociais sobre o que é, o que faz e como deveria ser o professor) e os processos concretos de troca realizados no fórum virtual.

No nosso caso, os significados mostram a tensão e a dialogicidade que aparecem quando os estudantes, os futuros docentes, elaboram motivações e diferentes modelos identitários. Sem dúvida, as tensões estabelecem-se entre imagens que têm, por sua vez, uma inscrição histórica na própria prática docente brasileira e que dão ao professor um sentido de transmissor de conhecimentos, portador do saber, como elemento guia para a construção de conhecimento significativo na aula.

0 mesmo podemos refletir em relação à motivação: o docente movido pelo amor e o altruísmo e aquele que elege ser professor por necessidade social. Sem dúvida, a contraposição destas imagens constitui um jogo de espelhos muito interessante para a configuração identitária dos futuros professores. No entanto, os processos de interação no fórum não mostram esse dinamismo, o que nos leva a refletir sobre a mediação introduzida pelos artefatos, no nosso caso, as TICs.

Segundo alguns autores (Wertsch, 2002; Nardi, 1996), a mediação da escrita nos ambientes virtuais poderia facilitar o surgimento de novas formas de intercâmbio caracterizadas pela reflexão metacognitiva e por outras formas de consciência da própria atividade. Entretanto, se situarmos as novas tecnologias em sua própria história - genealogia - as das tecnologias leitura-escrita -, poderemos constatar que a reflexividade crítica é apenas uma possibilidade entre muitas outras. Sem dúvida, as funções sócio-históricas do artefato leitura-escrita, desde a poética clássica até a internet, têm relação com a libertação, individualização, reflexão crítica ou o comunitarismo, mas, na mesma medida, se fizeram com a submissão, o gregarismo, o fanatismo o egoísmo.

No nosso estudo, encontramos alguns exemplos da complexidade que tais questões trazem para a construção da identidade docente. Há intervenções que expressam desacordos e contra-argumentações, exemplos que apontam reflexões críticas mais pessoais, independentes e elaboradas. Entretanto, estas formas de participação ocorrem com menos frequência, prevalecendo aquelas em que os participantes expressaram acordo e apoio às opiniões dos companheiros.

Desde nossa perspectiva, as intervenções que transmitem acordo ajudam na criação de comunidades e apontam as trocas genuínas entre os estudantes, sem chegar a uma reelaboração crítica do conteúdo expresso. Isto terá consequência no modo pelo qual os estudantes negociam imagens identitárias docentes que aparecem no fórum. Em geral, em suas participações, os estudantes vão 
expressando diferentes modos de ser professor, diferentes motivações e práticas docentes sem colocá-las realmente em crise e sem submetê-las a trocas críticas.

Os resultados analisados nos indicam o impacto das ferramentas mediacionais das TICs na formação docente, já que, por um lado, elas mostram toda a sua potencialidade na criação de espaços formativos ricos em informação e intercâmbios, mas, ao mesmo tempo, podem restringir a formação de profissionais reflexivos se não se promoverem intercâmbios comunicativos críticos e genuínos.

\section{Referências}

AYCOCK, Alan. Technologies of the self: Foucault and Internet discourse. Journal of Computer-Mediated Communication [On-line], Wisconsin-Milwaukke, Department of Anthropology University of Wisconsin-Milwaukke, 1(2), s/p, set., 1995.

BRUNER, Jerome. Actos de significado. Madrid: Alianza, 1998.

CARLUCCI, Ana Paula, GONZALEZ, Maria Fernanda; CASTRO-TEJERINA, Jorge. Estudo da identidade docente em um fórum de formação continuada na UAB/UnB, Brasil. In: // Congresso Internacional TIC e Educação: em direção à educação 2.0, 2012, Lisboa/Portugal, Ata do II Congresso Internacional TIC e Educação, Lisboa, Instituto de Educação, Universidade de Lisboa, 2012, página 2228-2239. Disponível em: <http:// ticeduca.ie.ul.pt/atas/atas.html>. Acesso em: 10 jan. 2013.

CAPURRO, Rafael. Information Technology and Technology of the self. Journal of Information Ethics, ACM, New York, USA, Magazine Ubiquity, 5(2), páginas 19-28, jun., 1996.

COLE, Michael. Psicología Cultural: una disciplina del pasado y del futuro. Madrid: Ediciones Morata, S. L. 1999.

COLL, César; FALSAFI, Leili. Learner identity. An educational and analytical tool. Revista de Educación, MEC, Espanha, 353, páginas 211-233, set-dez., 2010.

CUTLER, Richard. Technologies, relations, and selves. In: STRATE, Lance, JACOBSON, Ronald; GIBSON, Stephanie. (Eds.), Communication and cyberspace: Social interaction in an electronic environment. Crosskill, NJ: Hampton, 1996. p.317-333.

DE LA MATA, Manuel Luis; SANTAMARÍA, Andrés. La construcción del yo en escenarios educativos. Un análisis desde la psicología cultural. Revista de Educación, MEC, Espanha, 353, p.157-186, set-dez.; 2010.

DERVIN, Fred.; ABBAS, Yasmine. Introduction. In: ABBAS, Yasmine.; DERVIN, Fred. Digital Technologies of the Self. Newcastle: Cambridge Scholars Publishing, 2009. p. 1-14.

ENGESTRÖM, Yrjö. Learning by Expanding. Helsinku: orienta-Konsultit Oy, 1987. FLORES, Paula Quadros; FLORES, António. Inovar na educação: o moodle no processo 
de ensino/aprendizagem. V Conferência Internacional de Tecnologias de Informação e Comunicação na Educação. S/A. Disponível em: <http:// www.nonio.uminho.pt/ documentos/actas/actchal2007/047.pdf>. Acesso em: 22 mar. 2010.

HARRÉ, Rom. The singular self. An Introduction to the Psychology of Personhood. London: Sage, 1998.

HASTE, Helen. Identity, communities and citizenship. In: FACER, Keri (Ed.). Educational, Social and Technological Futures: A Report from the Beyond the Current Horizons Programme. Beyond Current Horizons: Technology, Children, Schools and Families. Bristol: Futurelab/Dept. of Children, Families and Schools, 2009. p.76-92.

KAPTELININ, Victor; NARDI, Bonnie. Acting with Techonology. Activity Theory and Interaction Desing. Cambridge, Massachusetts: The MIT Press, 2006.

KARGE, Martha. The Digital Self in Cyberspace. Wisconsin-Milwaukke University of Wisconsin Milwaukee. 1999.

KRESS, Gunther. Literacy in the new media age. New York: Routledge. 2003.

LANGHAM, Don. The common place MOO: Orality and literacy in virtual reality. Journal of Computer-Mediated Communication, Computer-mediated communication magazine, 1(3). 1994. Páginas 1-7. Disponível em: <http://www.december.com/cmc/mag/1994/ jul/moo.html>. Acesso em: 13 fev. 2013.

NARDI, Bonnie; O'DAY, Vicki. Information Ecologies. Using Technologies with heart. Cambridge, Massachusetts: The MIT Press, 1999.

NARDI, Bonnie. (ED.). Context \& Conciussness. Activity Theory and Human-Computer Interaction. Cambridge, Massachusetts: The MIT Press, 1996.

POLMAN, Joseph. The zone of proximal identity development in apprenticeship learning. Revista de Educación, MEC, Espanha, 353, p.129-155, set-dez., 2010.

PONTECORVO, Clotilde. Discutindo se aprende: interação social, conhecimento e escola. Porto Alegre: Artmed, 2005.

RIVA, Giuseppe; GALIMBERTI, Carlo. (Eds.) Actors, Artifacts and Inter-Actions. Outline for a Social Psychology of Cyberspace. Towards cyberpsychology: mind, cognition, and society in the Internet age. Amsterdan: IOS Press, 2001.

ROSA, Alberto; BLANCO, Florentino. Actuations of Identification in the games of identity. Social practice/Psychological Theorizing. Web Journal Social Practice/Psychological Theorizing. Artículo 7. 2007. p.1-20. Disponível em: <http://www.sppt-gulerce.boun. edu.tr/articles.htm>. Acesso em: 13 fev. 2013.

$\mathrm{SCHÖN}$, Donald. La formación de profesionales reflexivos. Hacia un nuevo diseño de la enseñanza y el aprendizaje en los profesores. Barcelona: Centro de Publicaciones del MEC y Paidós, 1992.

TURKLE, Sherry. Life on the Screen. Identity in the age of the Internet. New York: Touchstone, 1997.

How computers change the way we think. The Chronicle of Higher Education, v.50,n. 21, p. B26, 2004. 
VALENTINE, Jeremy. Information Technology, Ideology and Governmentality. Theory Culture Society, Los Angeles, London, New Delhi, Singapore: Sage Publications, 17(2), p.21-43, abr., 2000.

WENGER, Etienne. Communities of practice and social learning systems: the career of a concept. In: BLACKMORE, Chris. (Ed.) Social Learning Systems and communities of practice. Springer Verlag and the Open University, 2010. p.179-199.

.Communities of practice: Learning, Meaning, and Identity. Cambridge: Cambridge University Press, 1998.

WERTSCH, James. Voces de la mente. Un enfoque socio-cultural para el estudio de la acción mediada. Madrid: Visor, 1993.

Computer mediation, PBL, and Dialogicality. Distance Education, Australia, Journal of the Open and Distance Learning Association of Australia Inc, 23(1), p. 105108. DOI: 10.1080/01587910220124008, 2002.

WORTHAM, Stanton. The interdependence of social identification and learning. American Education Research Journal, Los Angeles, London, New Delhi, Singapore: Sage Publications, vol. 41, n. 3, p.715-750, set., 2004.

. Learning Identity: The Joint Emergence of Social Identity and Academic Learning. New York: Cambridge University Press, 2006.

. Listening for identity beyond the speech event. Teachers College Record, University of Pennsylvania, Graduate School of Education (GSE Publications), vol. 112, pp. 2848-2871,2010.

Recebido em julho de 2013

Aprovado março de 2014

Maria Fernanda Gonzalez é PhD em Psicologia pela Universidad Autónoma de Madrid e professora da Facultad de Psicologia da Universidad Nacional de Educación a Distancia, Madrid/Espanha. E-mail: fgonzalezapsi.uned.es

Jorge Castro-Tejerina é PhD em Psicologia pela Universidad Autónoma de Madrid eé professor da Faculdade de Psicologia da Universidad Nacional de Educación a Distancia, Madri/Espanha. E-mail: jorge.castrolapsi.uned.es

Ana Paula Carlucci é doutoranda do Programa de Pós-Graduação em Processos de Desenvolvimento Humano e Saúde, do Instituto de Psicologia - Universidade de Brasília, com bolsa do Programa de Doutorado Sanduíche no Exterior/Capes, entre 12/2011 e 11/2012, na Universidad Nacional de Educación a Distancia, com a co-orientação do Prof. Dr. Jorge Castro-Tejerina. E-mail: apcarluccidgmail.com 